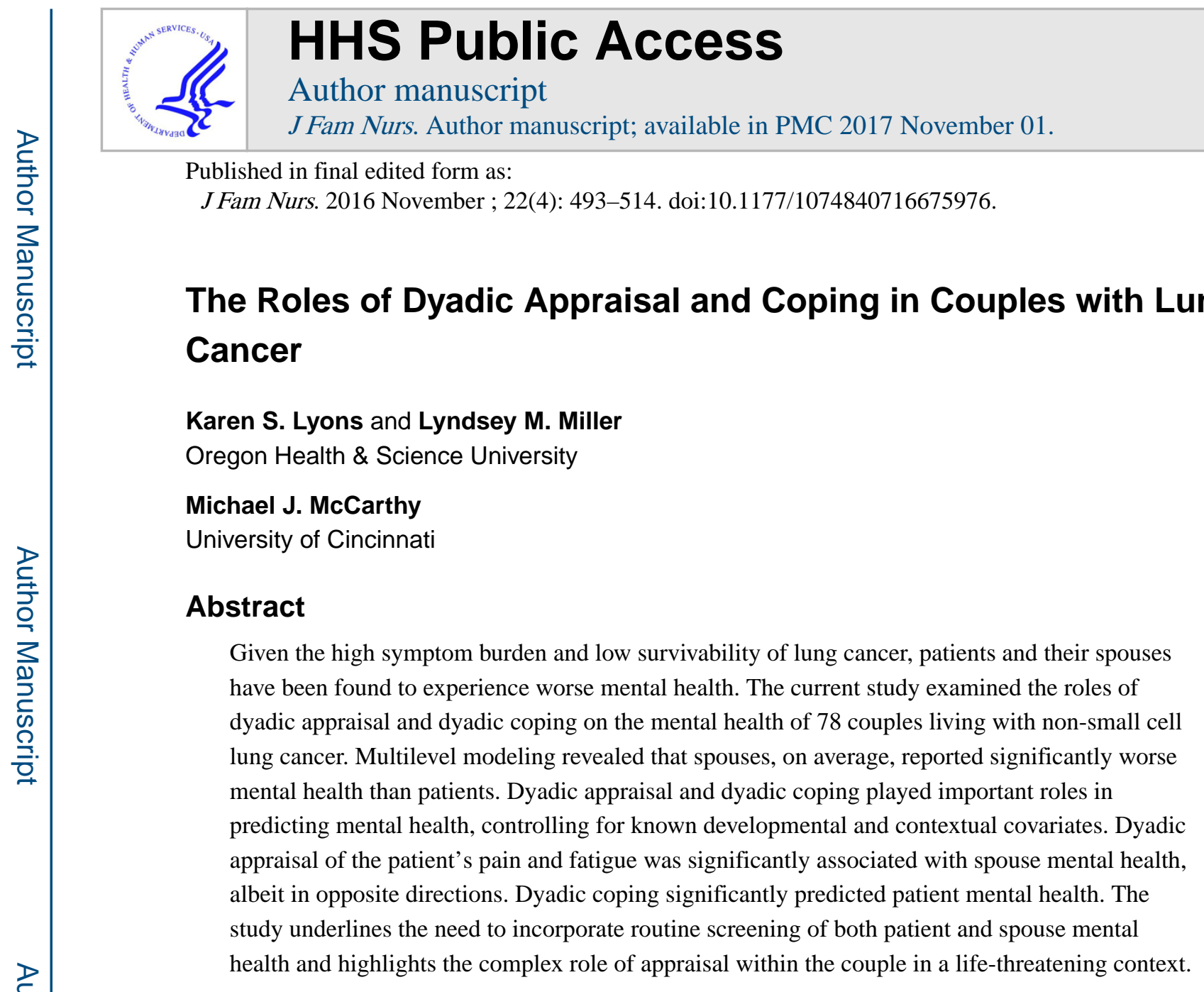

\title{
Keywords
}

Protective buffering; symptom incongruence; relationship quality; pain; fatigue

\begin{abstract}
Lung cancer is the most common cause of death from cancer worldwide (Ferlay et al., 2013) and the leading cause of cancer deaths in the U.S (American Cancer Society, 2012; Howlader et al.). Given the high symptom burden and low survivability of the disease, it is not surprising that lung cancer patients and their spouses experience poor mental health (Liao, Shun, Liao, Yang, \& Lai, 2014; Manne, Badr, \& Kashy, 2012; Milbury, Badr, \& Carmack, 2012; Mosher, Given, \& Ostroff, 2015). Indeed, some cancer research has found mental health to be poorest among lung cancer patients (Zabora, Brintzenhofeszoc, Curbow, Hooker, \& Piantadosi, 2001). Nevertheless, there is a dearth of research that has explicitly focused on the mental health of lung cancer couples using appropriate couple-level analyses. Notable exceptions have highlighted the vulnerability of lung cancer couples and the important roles of relationship quality and relationship maintenance behaviors to promote
\end{abstract}

Corresponding author: Karen S. Lyons, PhD, Associate Professor and PhD Program Director, School of Nursing, Oregon Health \& Science University, 3455 SW U.S. Veterans Rd., SN-ORD, Portland, OR 97239, Phone: 503-494-3975, Fax: 503-418-0903, lyonsk@ohsu.edu.

Conflict of Interest Statement

The authors have no conflict of interest to disclose. 
mental health (Badr, Acitelli, \& Carmack Taylor, 2008; Milbury et al., 2012). The current study aims to address this gap by examining the roles of dyadic appraisal and dyadic coping on the mental health of couples with lung cancer.

The developmental-contextual model of couples coping with illness proposes that couples work together as a unit to appraise, cope, and adjust to the illness experience over time (Berg \& Upchurch, 2007). An explicit strength of the model is that it moves beyond an individualistic approach to focus on the transactional nature of how patients and spouses influence one another (i.e., cross-spouse effects) and acknowledges the important roles that dyadic (shared) appraisal and dyadic coping strategies have for both members. The model purports that the appraisal, coping, and adjustment processes may differ depending on the developmental stage of the couple (e.g., middle-aged vs. older), namely, how normative and "expected" the illness is for the couple, as well as the various stages of the illness trajectory (e.g., early vs. late-stage disease). Finally, the framework includes proximal and distal contextual risk factors (e.g., relationship quality and gender) (Figure 1).

\section{Dyadic Appraisal}

Dyadic appraisal is conceptualized as dyadic (shared) illness representation, illness ownership (an "ours" vs. "mine" approach), or shared stressors (Berg \& Upchurch, 2007). Patients and spouses who share similar appraisals of the illness context have been found to experience better dyadic adjustment (Acitelli \& Badr, 2005; Cremeans-Smith et al., 2003; Li $\&$ Loke, 2014). One important way that patients and spouses may appraise the illness context similarly or differently is in relation to patient symptoms. Indeed, Berg and Upchurch (2007) outline the need for a dyadic perspective of illness representation as one way to understand the complex role of incongruent symptom perceptions within couples, citing inconsistent evidence regarding whether incongruent symptom perceptions (within couples) always lead to poorer dyadic adjustment. Shared recognition and perception of symptoms are thought to optimize the couple's ability to jointly manage illness and lead to better outcomes (Li \& Loke, 2014), but the context (e.g., gender, stage of disease) surrounding disparate appraisals (e.g., patient rating severity lower than a spouse) may alter the beneficial effects for patients and their spouses. Without moving beyond an individualistic approach to a dyadic perspective of this unique family unit, it is not possible to fully understand the complexity of how patients and their spouses converge or diverge in their appraisals, nor the implications of such similarity or differences for the couple.

Lung cancer patients have been found to experience significantly more symptoms and greater symptom severity than other cancer patients (Stommel, Kurtz, Kurtz, Given, \& Given, 2004). Pain and fatigue are among the most distressing symptoms for lung cancer patients (Broberger, Tishelman, \& von Essen, 2005; Oi-Ling, Man-Wah, \& Kam-Hung, 2005; Tishelman et al., 2005) and also among the most challenging for spouses to recognize (Broberger et al., 2005; Lyons, Lee, et al., 2014; McPherson \& Addington-Hall, 2003). Higher levels of incongruence between patient and spouse regarding patient symptoms may impair the ability of the couple to collaborate and manage the illness together (Acitelli \& Badr, 2005; Berg \& Upchurch, 2007; Li \& Loke, 2014), and given the rapid downward trajectory in lung cancer, can create clinical challenges (Zhang \& Siminoff, 2003). Indeed, 
exploratory evidence by the authors suggests symptom incongruence can have negative consequences for spouse adjustment (McCarthy \& Lyons, 2015), including higher levels of complicated grief post-bereavement (Lyons, Lee, et al., 2014). Few studies of symptom incongruence have used comprehensive and appropriate dyadic methodologies, nor examined the role of symptom incongruence on the mental health of couples. The small body of work in the broader illness literature has found patient-spouse incongruence in perceptions of patient pain and fatigue to be associated with worse mental health in both patient and spouse (Cano, Johansen, \& Franz, 2005; Cremeans-Smith et al., 2003). Thus, the present study operationalizes dyadic appraisal as the incongruence between patient and spouse regarding the patient's pain severity and level of fatigue (Figure 1).

\section{Dyadic Coping}

Berg and Upchurch (2007) conceptualize dyadic coping as a continuum of spousal involvement (e.g., uninvolved, supportive, collaborative, and control). Collaboration, or active engagement encompasses open communication, joint problem-solving and mutual disclosures. Some evidence suggests disclosures may only be beneficial when mutual or reciprocated (Manne et al., 2015; Manne et al., 2004) or when cancer is more severe (Kuijer et al., 2000). Alternatively, overprotection and control within couples often involves protective buffering (i.e., hiding, concealing worries). Patients experiencing illness tend to avoid communication in an attempt to protect their partner. This protective buffering has been associated with worse mental health in both cancer patients and spouses (Li \& Loke, 2014; Manne et al., 2015; Morgan, Small, Donovan, Overcash, \& McMillan, 2011; Robbins, Lopez, Weihs, \& Mehl, 2014; Song et al., 2012; Yu \& Sherman, 2015), increasing the need for open communication. The current study explores the concept of dyadic coping by examining the patient's engagement in protective buffering (Figure 1).

\section{Dyadic Adjustment}

Research has consistently found that both patients and spouses experience worse mental health as a result of the cancer experience (Kim et al., 2015; Milbury et al., 2012; Northouse, Williams, Given, \& McCorkle, 2012; Zwahlen, Hagenbuch, Jenewein, Carley, \& Buchi, 2011). Indeed, patients and spouses experience significantly higher depressive symptoms, anxiety and negative mood than age-matched controls (Costanzo, Ryff, \& Singer, 2009; Mitchell, Ferguson, Gill, Paul, \& Symonds, 2013). Depressive symptoms and anxiety of cancer patients and spouses have been found to covary (Hagedoorn, Sanderman, Coyne, Bolks, \& Tuinstra, 2008; Milbury et al., 2012; Robbins et al., 2014) making it particularly relevant to focus on the couple as the unit of analysis. Although the concept of dyadic adjustment has been described as psychosocial adjustment of the patient and spouse (Berg \& Upchurch, 2007), it has been operationalized in numerous ways (e.g., depressive symptoms, anxiety, psychological distress, mental health). The current study will measure dyadic adjustment with a global, well-established measure of mental health (Figure 1).

The current study is the first known study to simultaneously examine the roles of dyadic appraisal and dyadic coping on the mental health of couples with lung cancer. According to the developmental-contextual model, the concepts of dyadic appraisal and dyadic coping 
may play pivotal roles in determining couples who do well and those that do not. However, little research in lung cancer has taken a dyadic approach to the psychological adjustment of patients and their spouses. It is unknown if shared (congruent) symptom appraisals and more collaborative dyadic coping (i.e., low levels of protective buffering) will be associated with better adjustment (i.e., mental health) within couples, given the life-threatening nature of the illness and rapid trajectory. We hypothesize that patients and spouses will experience better mental health when the couple has lower symptom incongruence and lower levels of protective buffering by the patient, controlling for known contextual and developmental covariates, namely, patient age (Ayotte, Yang, \& Jones, 2010), patient gender (Hagedoorn et al., 2008), stage of disease, and relationship quality (Badr \& Carmack Taylor, 2008;

Carmack Taylor et al., 2008; Lyons, Bennett, et al., 2014).

\section{Method}

\section{Participants and Procedures}

Current data are drawn from a larger, longitudinal study of symptom incongruence and mental health in lung cancer patients and their family members providing care (Lyons, Bennett, et al., 2014; Lyons, Lee, et al., 2014). Data were collected separately from patient and family member at baseline, 3, 6, 9, and 12 months (follow-up interviews were brief and focused primarily on patient symptoms and function). The current study only involves baseline data for the sub-sample of 78 couples (patient and spouse/partner) due to the nature of the research question.

Patients were required to 1) have a primary diagnosis of invasive non-small cell lung cancer within the past 6 months, 2) be at least 18 years of age or older, 3) be able to speak English, and 4) have access to a telephone. Participants were recruited from a statewide cancer registry using rapid case ascertainment. Registry staff made initial contact with patients through a letter describing the study. Contact information for participants who mailed back a reply form was given to the study project director, who determined eligibility by telephone. Written informed consent and baseline interviews were conducted in-person and separately for patients and their spouses. Further detail has been previously described (Lyons, Lee, et al., 2014). Participants were compensated for the completion of each interview ( $\$ 10$ per participant, per interview). The study was approved by the Institutional Review Board at Oregon Health \& Science University.

\section{Measures}

Relationship quality-The Mutuality scale measures the positive aspects and interactive nature of relationship quality (Archbold, Stewart, Greenlick, \& Harvath, 1990). Patients and spouses responded to 15 items about their relationship with each other, using a Likert scale from 0 (not at all) to 4 (a great deal). High scores indicate higher levels of mutuality. The scale has exhibited high Cronbach's alpha values (.91 to .95) and strong construct validity (Archbold et al., 1990; Carter et al., 1998). The scale demonstrated strong internal consistency in this study (patient: $\mathrm{a}=.89$; spouse: $\mathrm{a}=.89$ ). 
Patient pain severity-Patient pain severity was measured using the 4-item subscale from the Brief Pain Inventory (BPI) (Cleeland \& Ryan, 1994). Items rate the patient's pain over the last week on a 0 (no pain) to 10 (pain as bad as you can imagine) scale for pain at its worst, least, on average, and right now. Subscale scores are created by averaging items, with higher scores indicating higher levels of pain. High Cronbach's alpha values have been exhibited for the subscale (Keller et al., 2004), including the current study (.90 for patient's self-report and .90 for spouse's proxy report).

Patient fatigue-Patient fatigue was measured using the 13-item fatigue scale of the Functional Assessment in Chronic Illness Therapy (FACIT) measure (Yellen, Cella, Webster, Blendowski, \& Kaplan, 1997). The measure, developed for use in cancer patients, assesses self-reported tiredness, weakness, and difficulty conducting usual activities due to fatigue. Each item is rated on a 0 (not all) to 4 (very much) scale based on fatigue over the past week. All but two items are reverse coded and then all items summed to create a scale score, with higher scores indicating less fatigue. The scale has demonstrated good construct validity (Yellen et al., 1997). The scale demonstrated strong internal consistency in the current study for both patient self-report $(a=.94)$ and spouse proxy report $(a=.92)$.

Protective buffering-Patients rated the extent to which they engaged in eight behaviors (e.g. "tried to keep your feelings or worries to yourself") using the Emotional-Intimacy Disruptive Behavior (EIDB) scale (Druley, Stephens, \& Coyne, 1997). Responses can range from 1 (rarely or none of the time) to 4 (most or all of the time), for a scale range of $8-32$. Higher scores indicate greater protective buffering. The EIDB scale demonstrated good internal consistency for this study $(a=.83)$.

Mental health-Patient and spouse mental health was measured using the Mental Component Scale (MCS) of the SF-36 v.2 (Ware \& Sherbourne, 1992). The SF-36 was designed as a generic measure of health for use in general population surveys and is wellestablished as a valid, reliable instrument that is sensitive to change over time (McHorney, Ware, Lu, \& Sherbourne, 1994). The SF-36 is composed of eight scales, each of which has 2-10 items. The Mental Component Scale (MCS) includes scales of vitality, social functioning, role-emotional, and mental health. The MCS has demonstrated strong internal consistency (Ware, Kosinski, \& Keller, 1994). Scores are transformed to 0-100, with higher scores indicating better health status. Cronbach's alpha for patients and spouses in the current study were .91 and .87 respectively.

\section{Analysis plan}

Multilevel modeling was used to analyze data at the level of the dyad to control for interdependencies in the data (Barnett, Marshall, Raudenbush, \& Brennan, 1993; Sayer \& Klute, 2005). The multivariate outcomes model estimates a latent score for each member of the couple (i.e., one for the patient and one for the spouse) controlling for the dependent nature of couple-level data and allows for the examination of both actor and cross-partner effects (Lyons, Sayer, Archbold, Hornbrook, \& Stewart, 2007). Dyadic models were tested using HLM 7 (Raudenbush, Bryk, \& Congdon, 2004). The first model was an unconditional (i.e., no covariates included) model of mental health within couples. This Level 1 (within- 
couple) model represents the mental health scores ( $Y$ ) for both patient and spouse as the sum of a latent true score ( $\beta_{1}$ for the patient and $\beta_{2}$ for the spouse) plus a residual term $r$ that captures measurement error and was specified as:

$$
\mathrm{Y}_{i j}=\beta_{1 j}\left(\mathrm{PATIENT}_{i j}\right)+\beta_{2 j}\left(\mathrm{SPOUSE}_{i j}\right)+\mathrm{r}_{i j}
$$

where $\mathrm{Y}_{i j}$ represents the mental health score $i$ in couple $j(i=1, \ldots . \mathrm{k}$ responses per couple). PATIENT is an indicator variable taking on a value of 1 if the response was obtained from a patient and 0 if the response was obtained from a spouse. SPOUSE is an indicator variable taking on a value of 1 if the response was obtained from a spouse and 0 if the response was obtained from a patient. Thus, $\beta_{1 j}$ and $\beta_{2 j}$ represent the patient's and spouse's latent mental health scores respectively.

The Level 2 (between-couple) model consisting of simultaneous regression equations with $\beta_{1 j}$ and $\beta_{2 j}$ serving as dependent variables can be specified as:

$$
\begin{array}{ll}
\beta_{1 \mathrm{j}}= & \gamma_{10}+\left[\gamma_{11} \text { Predictor }_{1}+\gamma_{1 \mathrm{n}} \text { Predictor }_{\mathrm{n}}\right]+u_{1 \mathrm{j}} \\
\beta_{2 \mathrm{j}}=\gamma_{20}+\left[\gamma_{21} \text { Predictor }_{1}+\gamma_{2 \mathrm{n}} \text { Predictor }_{\mathrm{n}}\right]+u_{2 \mathrm{j}}
\end{array}
$$

$\gamma_{10}$ and $\gamma_{20}$ are the Level 2 intercepts, representing average values of mental health for patient and spouse, respectively, adjusted for the effects of the predictors in each equation. This model included developmental (i.e., patient age), contextual (i.e., patient gender, stage of disease, and relationship quality), dyadic appraisal (i.e., patient-spouse incongruence regarding the patient's pain severity and fatigue), and dyadic coping (i.e., patient protective buffering) as predictors of dyadic mental health.

Dyadic appraisal scores-Dyadic appraisal was operationalized as patient-spouse incongruence, a second-order dyadic variable (Thompson \& Walker, 1982) created from both patients' and spouses' appraisals of lung cancer symptoms (pain and fatigue). Two HLM univariate dyadic outcomes models were used to generate empirical Bayes estimates of patient-spouse incongruence (differences between patient and spouse) regarding patient pain severity and fatigue. This approach to estimating latent dyadic incongruence scores is considered the most comprehensive and appropriate technique and has been described extensively (Cano et al., 2005; Lyons, Jones, Bennett, Hiatt, \& Sayer, 2013; Reamy, Kim, Zarit, \& Whitlatch, 2011; Sayer \& Klute, 2005).

\section{Results}

\section{Sample descriptives}

Table 1 presents background characteristics for the sample of 78 couples. Patients were significantly older $t(77)=2.68, p<.01$, reported poorer physical health $t(77)=6.53, p<$. 001 , and rated their pain $t(77)=-3.23, p<.01$ and fatigue $t(77)=4.16, p<.001$ less severely than spouses rated patient pain and fatigue. Spouses reported lower levels of relationship quality $t(77)=3.31, p<.001$ and worse mental health $t(77)=3.09, p<.01$ than patients. 


\section{Mental health}

Results of the Level 1 (within-dyad) model (Table 2) showed that patients and spouses reported moderate levels of mental health. Similar to the raw score data (Table 1), spouses, on average, reported significantly worse mental health than patients $(p<.01)$. A tau correlation of .34 indicates a moderate association between the mental health of patients and their spouses, reinforcing the need for a dyadic approach. Finally, there was significant variability around the average scores for both patients $\left(\chi^{2}=1084.5, p<.001\right)$ and spouses $\left(\chi^{2}=1086.2, p<.001\right)$ indicating significant heterogeneity in mental health across couples.

\section{Predicting dyadic mental health}

Patient protective buffering was significantly associated with patient mental health $t(69)=$ $-3.88, p<.001$, with patients engaging in higher levels of protective buffering more likely to have worse mental health. On the other hand, patient age $t(69)=4.20, p<.001$ and dyadic incongruence regarding pain $t(69)=2.25, p<.05$ and fatigue $t(69)=-2.01, p<.05$ were significantly associated with spouse mental health. Spouses experienced significantly worse mental health when patients were younger and when the couple experienced low levels of incongruence regarding the patient's pain severity, and when the couple experienced high levels of incongruence regarding the patient's level of fatigue. Together, the set of predictors accounted for $28 \%$ of the variance in patient mental health and $36 \%$ of the variance in spouse mental health.

Given the important role of protective buffering for patient mental health, additional descriptive analyses were conducted to shed light on factors associated with greater engagement in protective buffering. Protective buffering did not significantly differ by stage of disease $t(76)=1.73, p>.05$, nor was it significantly associated with patient age $(r=.17, p$ $>.05)$. However, it was significantly associated with higher levels of patient pain severity $(r$ $=.25, p<.05)$, patient fatigue $(r=.37, p<.001)$ and relationship quality $(r=-.31, p<.01)$ (as reported by the patient).

\section{Discussion}

The current study is the first known to simultaneously examine the roles of dyadic appraisal and a type of dyadic coping (i.e., patient protective buffering) on the mental health of lung cancer couples. Several findings are noteworthy. First, although both patients and spouses experienced moderate levels of mental health (Ware et al., 2007), spouses experienced significantly worse mental health than patients. Second, both dyadic incongruence and the patient's protective buffering played important roles in predicting mental health with incongruence being a significant predictor of spouse mental health and protective buffering a significant predictor of patient mental health. Finally, these effects remained when controlling for known developmental and contextual covariates.

Incongruence played an important role for spousal mental health, albeit in complex ways. Spouse mental health was worse when couples had disparate appraisals of the patient's fatigue, but more similar appraisals of the patient's pain severity. The finding regarding fatigue is consistent with the developmental-contextual framework, which purports the 
beneficial role of shared appraisal of the illness context. However, the protective nature of shared appraisal did not extend to patient mental health. Moreover, the finding regarding patient pain severity underscores the complexity of how couples communicate and make sense of the illness context, particularly in life-threatening illnesses. For instance, it is possible that pain, particularly at higher levels, may be more visible or disease-related for the spouse than fatigue (which can also be a side-effect of treatment and perceived as less threatening). Thus, a common, shared perception of pain may imply disease severity or prognosis to the spouse, and consequently greater demands and worry about the patient. Clearly, the benefits of shared appraisal of patient symptoms lie in greater ability for the couple to manage the illness together and optimize the patient's outcomes (Acitelli \& Badr, 2005; Berg \& Upchurch, 2007; Zhang \& Siminoff, 2003), but the interpretation and meaning given to those appraisals may lead to inconsistent influences on mental health. These findings reinforce the need to include dyadic appraisal variables (particularly second-order variables) and examine the complexity in what they are truly capturing. More work is needed to examine dyadic appraisals of the various aspects of the illness context and to replicate these findings in both life-threatening and chronic illness samples over time.

The level of protective buffering the patient was engaged in was the only significant predictor of patient mental health. Consistent with the developmental-contextual framework and previous research (Manne et al., 2015; Pasipanodya et al., 2012; Robbins et al., 2014), patients who reported higher levels of protective buffering were significantly more likely to experience worse mental health. What is of note is that this was the only significant predictor of patient mental health and did not significantly predict spouse mental health. Thus, the nature of the concept to "protect" the spouse appears, in fact, to have little impact on the spouse's mental health (in light of other variables in the model) and has a detrimental effect on the patient engaged in the behavior. Given the life-threatening context of lung cancer, it may well be that patients were more likely to engage in protective buffering when they felt there was more to conceal. Although protective buffering did not significantly differ by stage of disease in the current sample, higher levels of protective buffering were significantly associated with higher levels of pain severity and fatigue (as reported by the patient).

The current study is limited in its ability to tease apart the motivations behind such protective buffering, but the developmental-contextual model suggests the importance of examining both the distal (e.g., culture, gender) and proximal (e.g., stage of disease, relationship quality) context surrounding the couple. Moreover, the model advocates a truly dyadic approach to understanding the level of coping and collaboration within the couple by examining both the patient's and spouse's engagement in protective buffering (the latter was not possible in the current study) and the couple's perception of their communication and coping. Indeed, research suggests that communication and disclosure may be beneficial only if the social context is viewed as supportive (Lepore, Ragan, \& Jones, 2000), as patients may avoid communication to avoid negative responses (Cordova, Cunningham, Carlson, \& Andrykowski, 2001). Couples where both patients and spouses engage in protective buffering may be most at risk for negative outcomes. 
In addition, the current study also included several important developmental and contextual covariates of couple mental health. Findings are consistent with previous research that has found younger spouses to be at greater risk than older spouses due to the non-normative, offtime, nature of the illness (Carter, Lyons, Stewart, Archbold, \& Scobee, 2010; Harden, 2005). In other words, the experience of a life-threatening illness is not an expected, normative developmental stage in the lifespan for younger couples.

The study has several limitations. First, the sample size is relatively small, limiting the number of variables included in the model. As the primary focus of the current study was to examine the roles of dyadic appraisal and dyadic coping on general mental health, covariates were limited to those factors most salient in previous research and aligned with the developmental-contextual framework. For example, time since diagnosis and spouse physical health were not included in the final model (results were unchanged when they were included). Second, due to the cross-sectional nature of the data we are unable to untangle associations over time, as put forth by the framework. Replication of results, particularly given the unexpected nature of some of our findings, is needed in larger, longitudinal samples of both life-threatening and chronic illness contexts. Third, the recruitment of our sample from a population-based cancer registry using rapid case ascertainment enabled us to reach patients within a few months of diagnosis (the majority within 4 months) and attain a robust proportion of patients in advanced stage of disease (33\%). However, patient poor health was cited as a reason for refusal to participate, limiting our confidence to generalize to those patients experiencing significantly poor health soon after diagnosis. Finally, although protective buffering is a form of dyadic coping in the developmental-contextual model, the current study was unable to examine the role of spouse protective buffering, nor other forms of dyadic coping. Future research is needed to comprehensively assess various forms of dyadic coping from both patient and spouse perspectives to more fully appreciate how couples manage and navigate illness experiences in ways that are optimal to the health and well-being of both members.

Despite these limitations, we believe the study has several notable strengths and implications for research and practice. First, the study used appropriate dyadic methodology to be the first to simultaneously examine the roles of dyadic appraisal and a type of dyadic coping in couples with lung cancer, controlling for important covariates, most particularly perceptions of the quality of the relationship. We believe this approach greatly strengthens our findings. Second, we believe our use of second-order (Thompson \& Walker, 1982) latent variables to capture dyadic appraisals of the illness context is a significant advantage over previous research. Our findings underscore the benefit of operationalizing dyadic appraisal in terms of symptom incongruence, albeit by no means the only way to capture the dyad's appraisal of the illness context. Research has consistently shown that couples who view the illness experience as an interdependent team (embracing a "we-ness" approach to the experience) tend to develop more positive health related behaviors and experience more positive outcomes (Acitelli \& Badr, 2005; Hooker, Grigsby, Riegel, \& Bekelman, 2015; Rottmann et al., 2015). Indeed, recent research in heart failure has found care dyads with high levels of collaboration and shared appraisal to experience low levels of caregiver strain, despite severity of the patient's illness (Lee et al., 2015). Finally, by testing components of the developmental-contextual model, we believe our findings also contribute to our theoretical 
understanding of dyadic adjustment in lung cancer couples and the sometimes complex roles of dyadic appraisal and dyadic coping strategies within a life-threatening context.

Together, the findings of the current study support and emphasize the growing need for a dyadic and family perspective of the illness context, particularly in the practice setting. Viewing the couple as a unit, rather than separate individuals, raises awareness in healthcare providers about the potential vulnerability of couples who are disparate in their appraisals or struggling in their ability to collaborate. Nurses are particularly well-situated to broach and facilitate therapeutic conversations with the couple around challenging topics and to provide the couple with ways to minimize the fear and worry that can often impede open communication and mutual disclosure. Promoting a team-based, "ours" versus "mine" approach to the illness and collaborative management strategies may be particularly beneficial.

This study is one of the first known to test the major elements of the developmentalcontextual framework in lung cancer couples, highlighting areas where further work may be needed regarding the importance of meaning and interpretation of shared appraisals across various illnesses, and ways various shared appraisals may influence dyadic coping strategies by both members of the couple. The study reinforces the need to focus on the couple as a unit as has been noted by several nurse researchers (Li \& Loke, 2014; Northouse, 2012), to incorporate routine screening of spouse mental health in addition to the currently mandated screening of cancer patient's mental health per the American College of Surgeons Commission on Cancer, to solicit the perceptions of both members of the couple, and to continue to pursue interventions that facilitate more collaborative, open communication and support within the couple in ways that are adaptive to both patient and spouse.

\section{References}

Acitelli, LK., Badr, HJ. My illness or our illness? Attending to the relationship when one partner is ill. In: Revenson, TA.Kayser, K., Bodenmann, G., editors. Couples coping with stress: Emerging perspectives on dyadic coping. Washington, DC: American Psychological Association; 2005. p. 121-136.

American Cancer Society. Cancer facts and figures 2012. Atlanta: American Cancer Society; 2012.

Archbold PG, Stewart BJ, Greenlick MR, Harvath T. Mutuality and preparedness as predictors of caregiver role strain. Research in Nursing \& Health. 1990; 13:375-384. [PubMed: 2270302]

Ayotte BJ, Yang FM, Jones RN. Physical health and depression: A dyadic study of chronic health conditions and depressive symptomatology in older adults couples. Journals of Gerontology: Psychological Sciences. 2010; 65B:438-448. DOI: 10.1093/geronb/gbq033

Badr H, Acitelli LK, Carmack Taylor CL. Does talking about their relationship affect couples' marital and psychological adjustment to lung cancer? Journal of Cancer Survivorship. 2008; 2:53-64. DOI: 10.1007/s11764-008-0044-3 [PubMed: 18648987]

Badr H, Carmack Taylor CL. Effects of relationship maintenance on psychological distress and dyadic adjustment among couples coping with lung cancer. Health Psychology. 2008; 27:616-627. DOI: 10.1037/0278-6133.27.5.616 [PubMed: 18823188]

Barnett RC, Marshall NL, Raudenbush SW, Brennan RT. Gender and the relationship between job experiences and psychological distress: A study of dual-earner couples. Journal of Personality \& Social Psychology. 1993; 64:794-806. [PubMed: 8505708]

Berg CA, Upchurch R. A Developmental-Contextual model of couples coping with chronic illness across the adult life span. Psychological Bulletin. 2007; 133:920-954. [PubMed: 17967089] 
Broberger E, Tishelman C, von Essen L. Discrepancies and similarities in how patients with lung cancer and their professional and family caregivers assess symptom occurrence and symptom distress. Journal of Pain and Symptom Management. 2005; 29:572-583. [PubMed: 15963866]

Cano A, Johansen AB, Franz A. Multilevel analysis of couple congruence on pain, interference, and disability. PAIN®. 2005; 118:369-379. [PubMed: 16289795]

Carmack Taylor CL, Badr H, Lee JH, Fossella F, Pisters K, Gritz ER, Schover L. Lung cancer patients and their spouses: Psychological and relationship functioning within 1 month of treatment initiation. Annals of Behavioral Medicine. 2008; 36:129-140. DOI: 10.1007/s12160-008-9062-7 [PubMed: 18797978]

Carter JH, Lyons KS, Stewart BJ, Archbold PG, Scobee R. Does age make a difference in caregiver strain? Comparison of young versus older caregivers in ealry-stage Parkinson's disease. Movement Disorders. 2010; 25:724-730. DOI: 10.1002/mds.22888 [PubMed: 20201024]

Carter JH, Stewart BJ, Archbold PG, Inoue I, Jaglin J, Lannon M, ... Group TPS. Living with a person who has Parkinson's disease: The spouse's perspective by stage of disease. Movement Disorders. 1998; 13:20-28. [PubMed: 9452321]

Cleeland CS, Ryan KM. Pain assessment: Global use of the Brief Pain Inventory. Ann Acad Med Singapore. 1994; 23:129-138. [PubMed: 8080219]

Cordova MJ, Cunningham LLC, Carlson CR, Andrykowski MA. Social constraints, cognitive processing, and adjustment to breast cancer. Journal of Consulting and Clinical Psychology. 2001; 69:706-711. [PubMed: 11550737]

Costanzo ES, Ryff CD, Singer BH. Psychosocial adjustment among cancer survivors: Findings from a national survey of health and well-being. Health Psychology. 2009; 28:147-156. DOI: 10.1037/ a0013221 [PubMed: 19290706]

Cremeans-Smith JK, Stephens MAP, Franks MM, Martire LM, Druley JA, Wojno WC. Spouses' and physicians' perceptions of pain severity in older women with osteoarthritis: Dyadic agreement and patients' well-being. PAIN®. 2003; 106:27-34. [PubMed: 14581107]

Druley JA, Stephens MAP, Coyne JC. Emotional and physical intimacy in coping with Lupus: Women's dilemmas of disclosure and approach. Health Psychology. 1997; 16:506-514. [PubMed: 9386995]

Ferlay, J., Soerjomataram, I., Ervik, M., Dikshit, R., Eser, S., Mathers, C., ... Bray, F. GLOBOCAN 2012 v1.0, Cancer Incidence and Mortality Worldwide: IARC CancerBase No. 11 [Internet]. Lyon, France: 2013.

Hagedoorn M, Sanderman R, Coyne JC, Bolks HN, Tuinstra J. Distress in couples coping with cancer: A meta-analysis and critical review of role and gender effects. Psychological Bulletin. 2008; 134:1-30. DOI: 10.1037/0033-2909.134.1.1 [PubMed: 18193993]

Harden J. Developmental life stage and couples' experiences with prostate cancer. Cancer Nursing. 2005; 28:85-98. [PubMed: 15815178]

Hooker SA, Grigsby ME, Riegel B, Bekelman DB. The impact of relationship quality on health-related outcomes in heart failure patients and informal family caregivers: an integrative review. Journal of Cardiovascular Nursing. 2015; 30(4 Suppl 1):S52-63. [PubMed: 25955196]

Howlader, N., Noone, AM., Krapcho, M., Garshell, J., Miller, D., Alterkruse, SF., ... Cronin, KA. SEER Cancer Statistics Review, 1975-2011. National Cancer Institute; Retrieved August 18, 2014, from http://seer.cancer.gov/csr/1975_2011/, based on November 2013 SEER data submission, posted to the SEER web site, April 2014

Keller S, Bann CM, Dodd SL, Schein J, Mendoza TR, Cleeland CS. Validity of the Brief Pain Inventory for use in documenting the outcomes of patients with noncancer pain. Clinical Journal of Pain. 2004; 20:309-318. [PubMed: 15322437]

Kim Y, van Ryn M, Jensen RE, Griffin JM, Potosky A, Rowland JH. Effects of gender and depressive symptoms on quality of life among colorectal and lung cancer patients and their family caregivers. Psycho-oncology. 2015; 24:95-105. DOI: 10.1002/pon.3580 [PubMed: 24831223]

Kuijer RG, Ybema JF, Buunk BP, DeJong GM, Thijs-Boer F, Sanderman R. Active engagement, protective buffering, and overprotection: Three ways of giving support by intimate partners of patients with cancer. Journal of Social and Clinical Psychology. 2000; 19:256-275. 
Lee CS, Vellone E, Lyons KS, Cocchieri A, Bidwell JT, D’Agostino F, ... Riegel B. Patterns and predictors of patient and caregiver engagement in heart failure care: A multi-level dyadic study. International Journal of Nursing Studies. 2015; 52:588-597. DOI: 10.1016/j.ijnurstu.2014.11.005 [PubMed: 25468283]

Lepore SJ, Ragan JD, Jones S. Talking facilitates cognitive-emotional processes of adaptation to an acute stressor. Journal of Personality and Social Psychology. 2000; 78:499-508. [PubMed: 10743876]

Li Q, Loke AY. A literature review on the mutual impact of the spousal caregiver-cancer patients dyads: 'communication', 'reciprocal influence', and 'caregiver-patient congruence'. European Journal of Oncology Nursing. 2014; 18:58-65. DOI: 10.1016/j.ejon.2013.09.003 [PubMed: 24100089]

Liao YC, Shun SC, Liao WY, Yang PC, Lai YH. Quality of life and related factors in patients with newly diagnosed advanced lung cancer: a longitudinal study. Oncology Nursing Forum. 2014; 41:E44-55. DOI: 10.1188/14.ONF.E44-55 [PubMed: 24578085]

Lyons KS, Bennett JA, Nail LM, Fromme EK, Dieckmann N, Sayer AG. The role of patient pain and physical function on depressive symptoms in couples with lung cancer: A longitudinal dyadic analysis. Journal of Family Psychology. 2014; 28:692-700. DOI: 10.1037/fam0000017 [PubMed: 25090253]

Lyons KS, Jones KD, Bennett RM, Hiatt SO, Sayer AG. Couple perceptions of fibromyalgia symptoms: The role of communication. PAIN®. 2013; 154:2417-2426. DOI: 10.1016/j.pain. 2013.07.018 [PubMed: 23872105]

Lyons KS, Lee CS, Bennett JA, Nail LM, Fromme EK, Hiatt SO, Sayer AG. Symptom incongruence trajectories in lung cancer dyads. Journal of Pain and Symptom Management. 2014; 48:10311040. DOI: 10.1016/j.jpainsymman.2014.02.004 [PubMed: 24747222]

Lyons KS, Sayer AG, Archbold PG, Hornbrook MC, Stewart BJ. The Enduring and Contextual Effects of Physical Health and Depression on Care Dyad Mutuality. Research in Nursing \& Health. 2007; 30:84-98. DOI: 10.1002/nur.20165 [PubMed: 17243110]

Manne S, Badr H, Kashy DA. A longitudinal analysis of intimacy processes and psychological distress among couples coping with head and neck or lung cancers. Journal of Behavioral Medicine. 2012; 35:334-346. DOI: 10.1007/s10865-011-9349-1 [PubMed: 21556790]

Manne S, Kissane D, Zaider T, Kashy DA, Lee D, Heckman C, Virtue SM. Holding back, intimacy, and psychological and relationship outcomes among couples coping with prostate cancer. Journal of Family Psychology. 2015

Manne S, Ostroff J, Rini C, Fox K, Goldstein L, Grana G. The interpersonal process model of intimacy: The role of self-disclosure, partner disclosure, and partner responsiveness in interactions between breast cancer patients and their partners. Journal of Family Psychology. 2004; 18:589_ 599. [PubMed: 15598164]

McCarthy MJ, Lyons KS. Incongruence between stroke survivor and spouse perceptions of survivor functioning and effects on spouse mental health: A mixed-methods pilot study. Aging \& Mental Health. 2015; 19:46-54. DOI: 10.1080/13607863.2014.913551 [PubMed: 24831861]

McHorney CA, Ware JE Jr, Lu JF, Sherbourne CD. The MOS 36-item Short-Form Health Survey (SF-36): III Tests of data quality, scaling assumptions, and reliability across diverse patient groups. Medical Care. 1994; 32:40-66. [PubMed: 8277801]

McPherson CJ, Addington-Hall JM. Judging the quality of care at the end of life: can proxies provide reliable information? Social Science \& Medicine. 2003; 56:95-109. [PubMed: 12435554]

Milbury K, Badr H, Carmack CL. The role of blame in the psychosocial adjustment of couples coping with lung cancer. Annals of Behavioral Medicine. 2012; 44:331-340. DOI: 10.1007/ s12160-012-9402-5 [PubMed: 22893024]

Mitchell AJ, Ferguson DW, Gill J, Paul J, Symonds P. Depression and anxiety in long-term cancer survivors compared with spouses and healthy controls: A systematic review and meta-analysis. Lancet Oncology. 2013; 14:721-732. DOI: 10.1016/s1470-2045(13)70244-4 [PubMed: 23759376]

Morgan MA, Small BJ, Donovan KA, Overcash J, McMillan SC. Cancer patients with pain: The spouse/partner relationship and quality of life. Cancer Nursing. 2011; 34:13-23. DOI: 10.1097/ NCC.0b013e3181efed43 [PubMed: 21139453] 
Mosher CE, Given BA, Ostroff JS. Barriers to mental health service use among distressed family caregivers of lung cancer patients. European Journal of Cancer Care. 2015; 24:50-59. DOI: 10.1111/ecc.12203 [PubMed: 24761985]

Northouse LL. Helping patients and their family caregivers cope with cancer. Oncology Nursing Forum. 2012; 39:500-506. [PubMed: 22940514]

Northouse LL, Williams AL, Given BA, McCorkle R. Psychosocial care for family caregivers of patients with cancer. Journal of Clinical Oncology. 2012; 30(11):1227-1234. DOI: 10.1200/JCO. 2011.39.5798 [PubMed: 22412124]

Oi-Ling K, Man-Wah D, Kam-Hung D. Symptom distress as rated by advanced cancer patients, caregivers and physicians in the last week of life. Palliative Medicine. 2005; 19:228-233. [PubMed: 15920937]

Pasipanodya EC, Parrish BP, Laurenceau J, Cohen LH, Siegel SD, Graber EC, Belcher AJ. Social constraints on disclosure predict daily well-being in couples coping with early-stage breast cancer. Journal of Family Psychology. 2012; 26:661-667. [PubMed: 22686265]

Raudenbush, SW., Bryk, AS., Congdon, R. Hierarchical linear and nonlinear modeling. Lincolnwood, IL: SSI; 2004.

Reamy AM, Kim K, Zarit SH, Whitlatch CJ. Understanding discrepancy in perceptions of values: Individuals with mild to moderate dementia and their family caregivers. The Gerontologist. 2011; 51:473-483. DOI: 10.1093/geront/gnr010 [PubMed: 21383111]

Robbins ML, Lopez AM, Weihs KL, Mehl MR. Cancer conversations in context: Naturalistic observation of couples coping with breast cancer. Journal of Family Psychology. 2014; 28:380390. DOI: 10.1037/a0036458 [PubMed: 24730380]

Rottmann N, Hansen DG, Larsen PV, Niicolaisen A, Flyger H, Johansen C, Hagedoorn M. Dyadic coping within couples dealing with breast cancer: A longitudinal, population-based study. Health Psychology. 2015; 34:486-495. DOI: 10.1037/hea0000218 [PubMed: 25730611]

Sayer, AG., Klute, MM. Analyzing couples and families: Multilevel methods. In: Bengtson, VL.Acock, AC.Allen, KR.Dilworth-Anderson, P., Klein, DM., editors. Sourcebook on Family Theory and Research. Thousand Oaks, CA: Sage; 2005. p. 289-313.

Song L, Northouse LL, Braun TM, Cimprich B, Ronis DL, Mood DW. Study of dyadic communication in couples managing prostate cancer: a longitudinal perspective. Psycho-oncology. 2012; 21:72-81. DOI: 10.1002/pon.1861 [PubMed: 20967920]

Stommel M, Kurtz ME, Kurtz JC, Given CW, Given B. A longitudinal analysis of the course of depressive symptomatology in geriatric patients with cancer of the breast, colon, lung, or prostate. Health Psychology. 2004; 23:564-573. [PubMed: 15546224]

Thompson L, Walker AJ. The dyad as the unit of analysis: Conceptual and methodological issues. Journal of Marriage and the Family. 1982; 44:889-900.

Tishelman C, Degner LF, Rudman A, Bertilsson K, Bond R, et al. Symptoms in patients with lung carcinoma: Distinguishing distress from intensity. Cancer. 2005; 104:2013-2021. [PubMed: 16178002]

Ware, JE., Kosinski, M., Bjorner, JB., Turner-Bowker, DM., Gandek, B., Maruish, ME. User's manual for the SF-36v2TM Health Survey. 2. Lincoln, RI: QualityMetric Incoporated; 2007.

Ware, JE., Kosinski, M., Keller, S. Physical and mental health summary scales: A user's manual. Boston, MA: Health Assessment Lab; 1994.

Ware JE, Sherbourne CD. The MOS 36-Item Short-Form Health Survey (SF-36). I. Conceptual framework and item selection. Medical Care. 1992; 30:473-483. [PubMed: 1593914]

Yellen SB, Cella D, Webster K, Blendowski C, Kaplan E. Measuring fatigue and other anemia-related symptoms with the Functional Assessment of Cancer Therapy (FACT) measurement system. Journal of Pain and Symptom Management. 1997; 13:63-74. [PubMed: 9095563]

Yu Y, Sherman KA. Communication avoidance, coping and psychological distress of women with breast cancer. Journal of Behavioral Medicine. 2015; 38:565-577. DOI: 10.1007/ s10865-015-9636-3 [PubMed: 25804374]

Zabora J, Brintzenhofeszoc K, Curbow B, Hooker C, Piantadosi S. The prevalence of psychological distress by cancer site. Psycho-oncology. 2001; 10:19-28. [PubMed: 11180574] 
Zhang AY, Siminoff LA. Silence and cancer: Why do families and patients fail to communicate? Health Communication. 2003; 15:415-429. [PubMed: 14527866]

Zwahlen D, Hagenbuch N, Jenewein J, Carley MI, Buchi S. Adopting a family approach to theory and practice: Measuring distress in cancer patient-partner dyads with the distress thermometer. Psychooncology. 2011; 20:394-403. DOI: 10.1002/pon.1744 [PubMed: 20878839] 


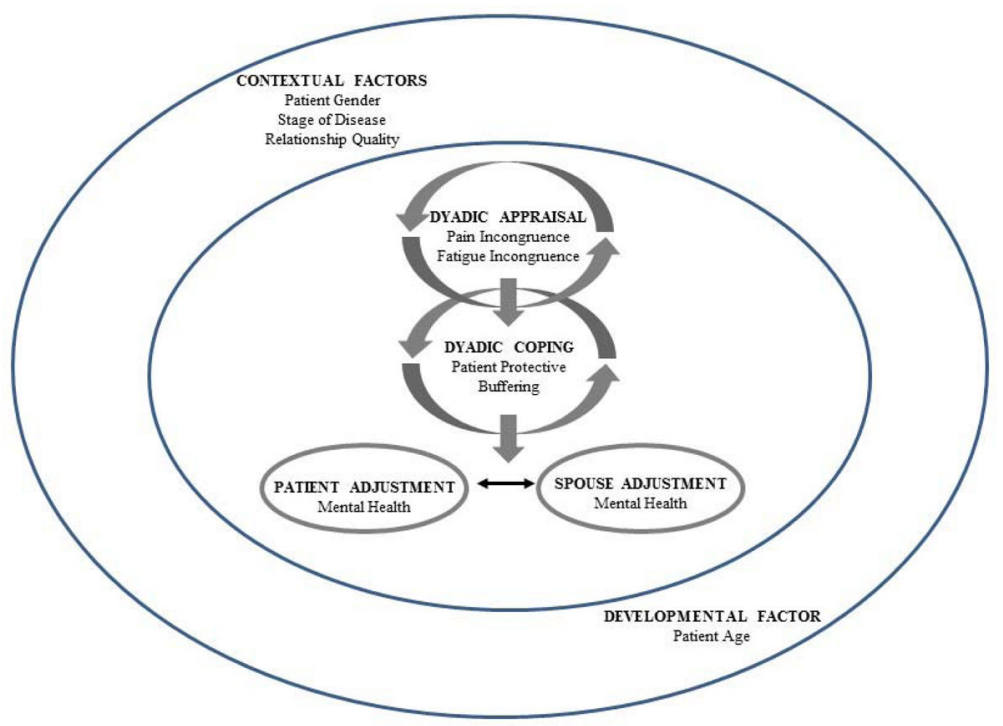

Figure 1.

Adapted development-contextual model of coping with illness. Source: Berg \& Upchurch, 2007 


\section{Table 1}

Patient and Spouse Characteristics ( $\mathrm{N}=78$ Couples)

\begin{tabular}{lll}
\hline Characteristic & Patients & Spouses \\
\hline Age (years), mean $( \pm$ SD) & $68.08(11.60)$ & $66.23(11.48)^{* *}$ \\
Women $(\%)$ & 33.3 & 67.9 \\
White $(\%)$ & 93.6 & 94.9 \\
Attended some college $(\%)$ & 48.7 & 65.4 \\
Stage IV disease $(\%)$ & 36.0 & - \\
Month since diagnosis, mean $( \pm$ SD) & $3.7(2.1)$ & - \\
Years together, mean $( \pm$ SD) & $36.06(17.2)$ & - \\
Physical health, mean $( \pm$ SD) & $37.4(10.5)$ & $48.6(10.9)^{* * *}$ \\
Relationship quality, mean $( \pm$ SD) & $3.6(0.4)$ & $3.4(0.5)^{* * *}$ \\
Raw score rating of patient pain, mean $( \pm$ SD) & $2.2(2.1)$ & $2.8(2.0)^{* *}$ \\
Raw score rating of patient fatigue, mean $( \pm$ SD) & $30.2(12.3)$ & $25.6(11.2)^{* * *}$ \\
Patient protective buffering, mean $( \pm$ SD) & $14.1(4.6)$ & - \\
Mental health, mean $( \pm$ SD) & $50.8(10.6)$ & $46.5(10.5)^{* *}$ \\
\hline
\end{tabular}

Note.

${ }^{a}$ Higher scores indicate less fatigue.

${ }^{*} p<.05$.

*** $p<.01$.

*** $p<.001$. 


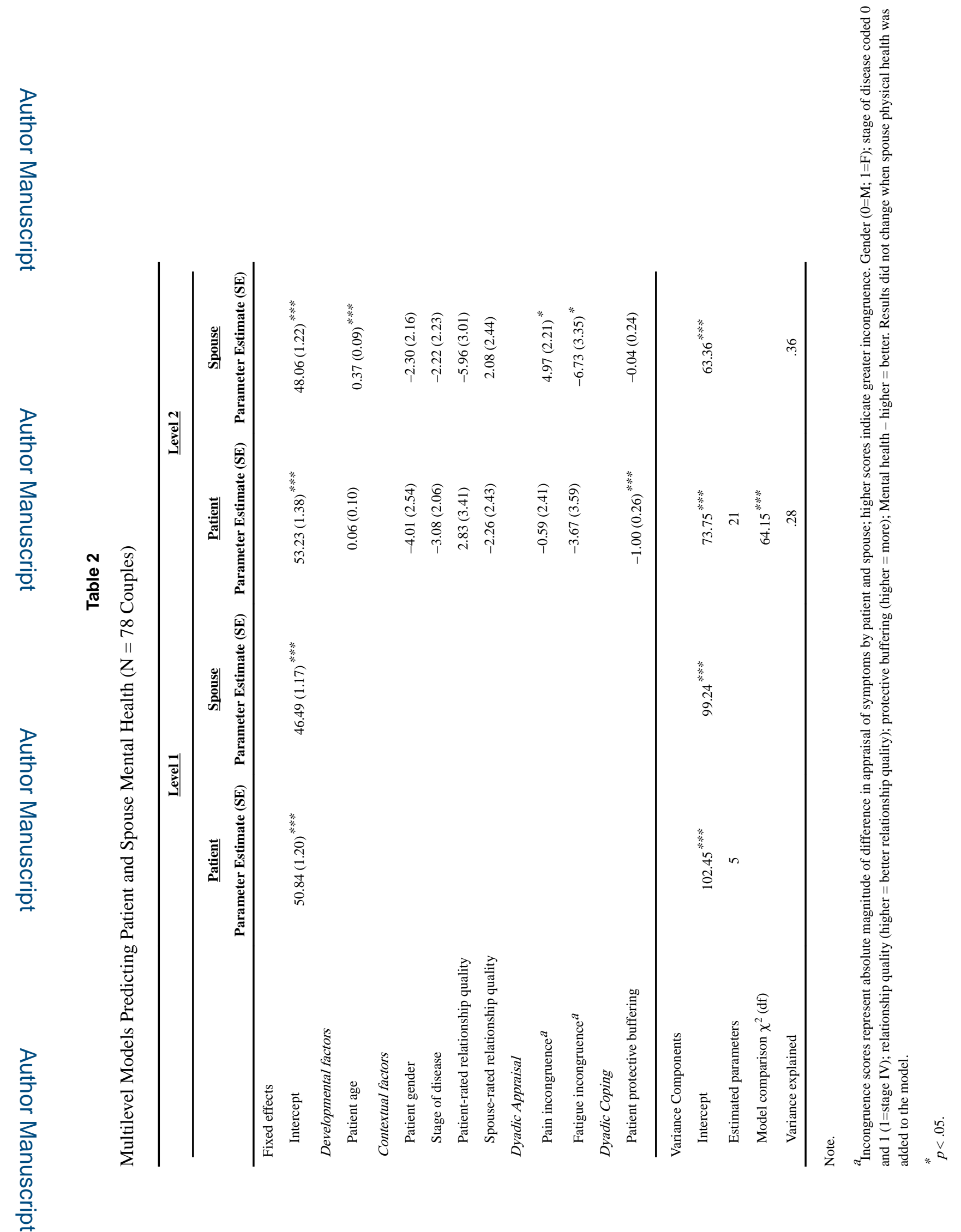

J Fam Nurs. Author manuscript; available in PMC 2017 November 01. 

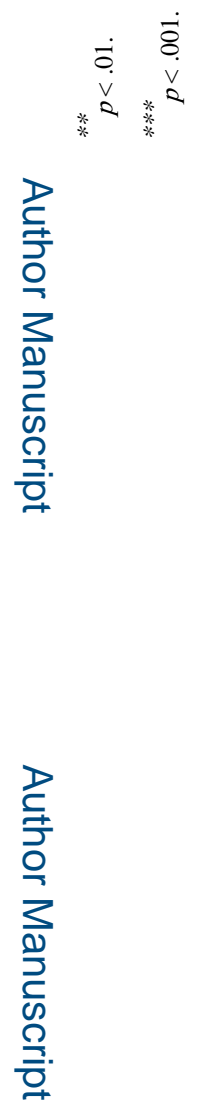

로을

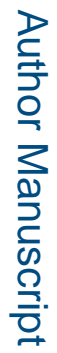

J Fam Nurs. Author manuscript; available in PMC 2017 November 01. 